Dear author,

Please note that changes made in the online proofing system will be added to the article before publication but are not reflected in this PDF.

We also ask that this file not be used for submitting corrections. 


\title{
Long-term decay heat removal in a submerged SMR
}

\author{
Marco Santinello*, Marco Ricotti \\ Politecnico di Milano, Dept. of Energy - CeSNEF-Nuclear Engineering Division, via La Masa 34, 20156 Milano, Italy
}

\section{A R T I C L E I N F O}

\section{Article history:}

Received 21 June 2018

Received in revised form 8 March 2019

Accepted 13 March 2019

Available online $\mathrm{xxxx}$

\section{Keywords:}

SMR

Passive safety

Submerged reactor

Long-term cooling

\begin{abstract}
A B S T R A C T
Following the Fukushima-Daiichi nuclear accident in March 2011, innovations are needed to improve the reliability of new generation nuclear power plants toward scenarios where electrical power and ultimate heat sink are lost. This paper describes an integral design and basic passive safety strategy of a Small Modular Reactor (SMR) submerged in the sea or in an artificial lake, then performing a preliminary analysis of the long-term decay heat removal. The analysis considers a pressurized reactor placed in a horizontal cylindrical hull, which is surrounded by the external water. The simulated system is based on the Flexblue concept, developed by French company DCNS (now Naval Group). The object of the investigation is the natural circulation in the submerged containment, which is the key component for the long-term cooling. Following a rupture in the primary circuit, decay heat must be removed according to a fully passive safety strategy for an indefinitely long period. The purpose of this work is to study the effectiveness of a sump natural circulation flow to cool the fuel rods, up to several days after the scram. Decay heat generates steam in the core, which is released in the containment and condensed on the metal surface, transferring the heat to the exterior. Relap5-Mod3.3 has been employed to simulate the accident scenario. Results show the consistency of the safety principles and stimulate experimental investigations. However, the sensitivity analysis identifies the nodalization of the reactor containment as a modeling and numerical issue, deserving further analyses.
\end{abstract}

(c) 2019 Published by Elsevier Ltd.

\section{Introduction}

The accident at the Fukushima-Daiichi nuclear power plant on March 11th, 2011 put on evidence the need for the nuclear community to be prepared for unexpected circumstances that may go beyond the design basis events. Even with large safety margins and good operation and maintenance practices, the, albeit remote, possibility of high consequence situations can never be excluded (IAEA, 2016-a). Fukushima-Daiichi accident was initiated by a series of three events: (i) off-site power distribution failed after the 9.0 magnitude earthquake, (ii) emergency diesel generators were flooded and thus unavailable and (iii) the transportation to the site and start-up of back-up equipment could be possible only several days after the reactor scram, because of the damages of the tsunami (Blandford and Ahn, 2012). Such sequence had not been predicted and the power plant was not prepared to handle it. Emergency cooling was not successful because several components, such as the Isolation Condenser (IC), the Reactor Core Isolation Cooling (RCIC) system and the High-Pressure Coolant-

\footnotetext{
* Corresponding author.

E-mail addresses: marco.santinello@polimi.it (M. Santinello), marco.ricotti@ polimi.it (M. Ricotti).
}

Injection system (HPCI), did not work properly in absence of electrical power. According to Tokyo Electric Power COmpany (TEPCO) estimates, Unit 1 was left without any water injection for $14 \mathrm{~h}$ and 9 min, while Unit 2 and Unit 3 lost cooling capabilities for approximately 6 and a half hours (TEPCO, 2011). This led to the melting of all the fuel in Unit 1,57\% of the fuel in Unit 2 and a large part of the fuel in Unit 3 (Holt et al., 2012). Basically, Fukushima-Daiichi accident emphasized that operating nuclear reactors may show strong difficulties in facing the Loss of Onsite/Offsite Power (LOOP) scenario, which led to the Loss of Ultimate Heat Sink (LUHS). Hence, nowadays novel reactors are characterized by a very strong attention to the development of passive safety systems. Considering pressurized water designs, after Fukushima guaranteeing an adequate core cooling through natural circulation for a very long period, without the need of AC power and human intervention, has become an important feature for the safety strategy of many Gen III+ designs.

A passive safety strategy assumes paramount importance in Small Modular Reactor (SMR), where compactness and simplified layout are the key aspects of the design. Recently, the IAEA (IAEA, 2016-a) has discussed the most important safety features employed in existing reactors and advanced designs of watercooled SMRs. Among the most innovative ideas, placing the nuclear 
reactor containment in a submerged environment has gained a lot of interest in recent years. The concept consists of having cold water that surrounds a large metal containment, which hosts the Reactor Pressure Vessel (RPV). Steam can be released in the internal atmosphere and condenses in contact with the inner surface, thus rejecting decay heat to the external water. This concept has been introduced in some innovative SMR designs, such as NuScale (Reyes Jr., 2012) and Westinghouse SMR (Smith and Wright, 2012): the reactor is immersed in a large pool, which offer a grace period determined by the total water inventory and heat transfer is effective until the water is sufficiently cold. Alternatively, if the metal containment is placed into the sea or in an artificial lake, the grace period given by the cooling process is potentially unlimited. Santinello et al. (Santinello et al., 2017) performed a numerical investigation about this aspect: they observed that the decay heat cannot influence significantly the temperature of the sink and such heat transfer process is very effective. The water of the sea/lake is a large reservoir acting as a permanent heat sink. This concept can satisfy high levels of nuclear safety, owning some characteristics that are unique in the current nuclear scenario.

In recent years, some transportable and sea-based SMRs have been designed for offshore operation, exploiting the safety benefits of a permanent heat sink. The main purpose of these reactors is to satisfy the energy needs in regions of the world where land is scarce, isolated or just unsuitable for the construction of a nuclear or oil\&gas power plants. This is, for instance, the case of remote areas with large natural resources, islands or highly populated areas under the threat of natural hazards. Off-shore SMRs can be classified into floating and steady operation. Floating barges hosting a small reactor for electricity production are the KLT-40S (Kuznetsov, 2012) and the ACPR50S (IAEA, 2016-b), the former under commissioning in Russian Federation, the latter under construction in China. Alternatively, the reactor can be set underwater, moored on the seafloor. This option is appearing quite attractive, as the Fukushima accident calls our nuclear industry to better consider extreme external events, like a tsunami, in the design of NPPs. Electric Boat (General Dynamics Electric Boat Division, 1971) and Herring (Herring, 1993) investigated subsea reactor designs in the 1970's and 1990's respectively. These projects stayed at the paper stage. Nowadays, the progresses in subsea oil\&gas technologies, submarine cables for offshore renewables and in shipbuilding techniques make offshore power reactors more feasible than before. Based on its experience in the design, fabrication, maintenance and dismantling of nuclear-powered submarines and ships, in 2014 the French company DCNS (now Naval Group) presented the Flexblue concept (Haratyk et al., 2014), a subsea and fully transportable nuclear power plant. Furthermore, other two con- cepts of offshore reactors can be found in literature. The Offshore Floating Nuclear Plant (OFNP) concept developed by Massachusetts Institute of Technology (MIT - United States) represents another solution for steady-operation design (Buongiorno et al., 2016): the reactor is built on a platform in a shipyard, transferred on the site within territorial waters and anchored in relatively deep water $(100 \mathrm{~m})$. Also, an ocean reactor based on the SMART design (Kim et al., 2014-b) has been proposed by the Korea Advanced Institute of Science \& Technology (KAIST - South Korea): the reactor operates on an offshore gravity-based structure, improving the safety from tsunamis and earthquakes.

This paper presents the results of a 1D system-code numerical investigation about the long-term core cooling process of a pressurized SMR placed on the seafloor, after a rupture of the primary circuit. The reference system is a submerged reactor, whose concept is sketched in Fig. 1. The purpose of the study is to observe if the sump natural circulation flow, which begins several hours after the depressurization and the containment flooding, succeeds in appropriately cooling the fuel rods for an indefinitely long period. In particular, the focus of the study concerns the long-term phase: the simulation strategy is aimed at assessing if the sump natural circulation flow is sustainable also when the decay power has reached very low values. The following sections summarize proposals for an integral reactor configuration (Section 2) and safety strategy (Section 3) for a submerged SMR. Then, Section 4 describes the simulation activity on the long-term cooling scenario: modeling strategy, results of the reference simulations, sensitivity analysis on the nodalization of the containments, validation issues.

\section{Integral design for submerged SMR}

The reactor to be placed inside the submerged containment must satisfy two constraints, determined by (i) safety and (ii) manufacturing.

(i) The power output is determined by the heat transfer capacity through the hull, to avoid overheating of the fuel rods during the emergency decay heat removal just after the scram. The mentioned study by Santinello et al. (2017) faced this problem, observing that the presence of a painting layer on the external surface, necessary to protect the hull from chemical degradation, drastically reduces the heat flux. However, the study also allowed determining the maximum power output at $500 \mathrm{MW}_{\mathrm{th}}$, with respect to decay heat removal capability.

Sea or Lake

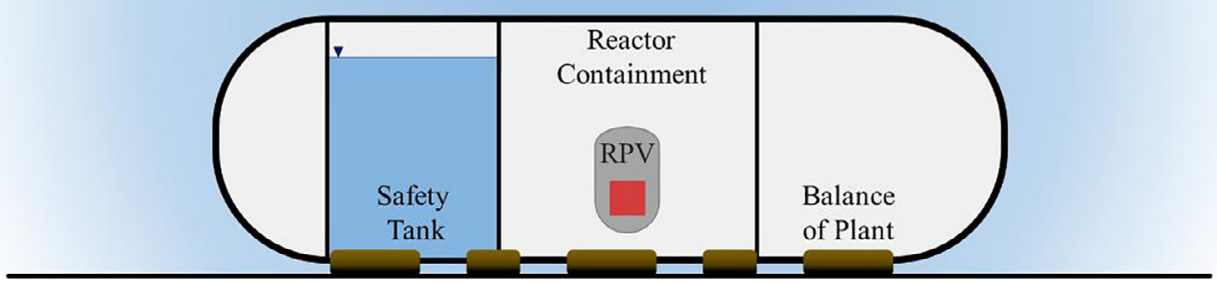

Fig. 1. Concept of a submerged SMR 
(ii) To ensure transportability and in-factory fabrication, the reactor must lie in a horizontal cylindrical hull, whose diameter is limited by manufacturing capacity and economic reasons. The Flexblue case, which is the reference design for this concept, considered $14 \mathrm{~m}$ as maximum diameter for the hull (Haratyk et al., 2014).

In addition, another requirement of the reactor design is the adaptability to a fully passive safety strategy, which is a keystone of the submerged concept.

In the past years, a couple of options have been proposed for the Flexblue case, i.e. a loop-type reactor and SCOR-F reactor from CEA (NUSMoR consortium, 2014). For different reasons, these two solutions may be inappropriate for a submerged reactor (Santinello and Ricotti, 2018) (Santinello, 2018). Politecnico di Milano is working on an integral SMR concept, suitable to operate in a submerged hull and based on a scaled version of the IRIS design (Carelli et al., 2004). The new proposal is named IRIS-160 and is described in reference (Santinello and Ricotti, 2018). The primary components have been revisited in order to reduce the thermal power output from 1000 to $500 \mathrm{MWth}$ and the reactor height from 22 to less than $14 \mathrm{~m}$. The analysis regards the reactor core, the control rods driving mechanism, the steam generator, the primary pumps and the pressurizer.

The reactor core is the IRIS standard PWR fuel assembly: a configuration made of 89 fuel assemblies with 264 fuel rods in a $17 \times 17$ square array. The active height of the fuel elements has been scaled down to $2 \mathrm{~m}$, as in NuScale and SMART (International Atomic Energy Agency, 2016), in order to reduce the power output. The Control Rods Driving Mechanism is placed above the core, inside the RPV, thus eliminating the control rod ejection accident. Like in IRIS, for the IRIS-160 the use of axial "spool-type" pumps has been assumed. The pressurizer is integrated in the RPV dome and has an ellipsoidal shape. The volume to power ratio is much higher than conventional PWR (1.6 times the AP1000), thus avoiding the need of sprayers. The Steam Generator (SG) design for IRIS-160 has undergone large modifications with respect to the IRIS original design. To reduce the RPV diameter, a layout with two or four helical SG modules co-axial to the barrel has been proposed. Preliminary calculations have been made with a lumped parameter model to estimate the SG diameter necessary to allow the heat transfer of $500 \mathrm{MW}_{\text {th }}$, given the constraints on maximum tube length and SG height. The resulting

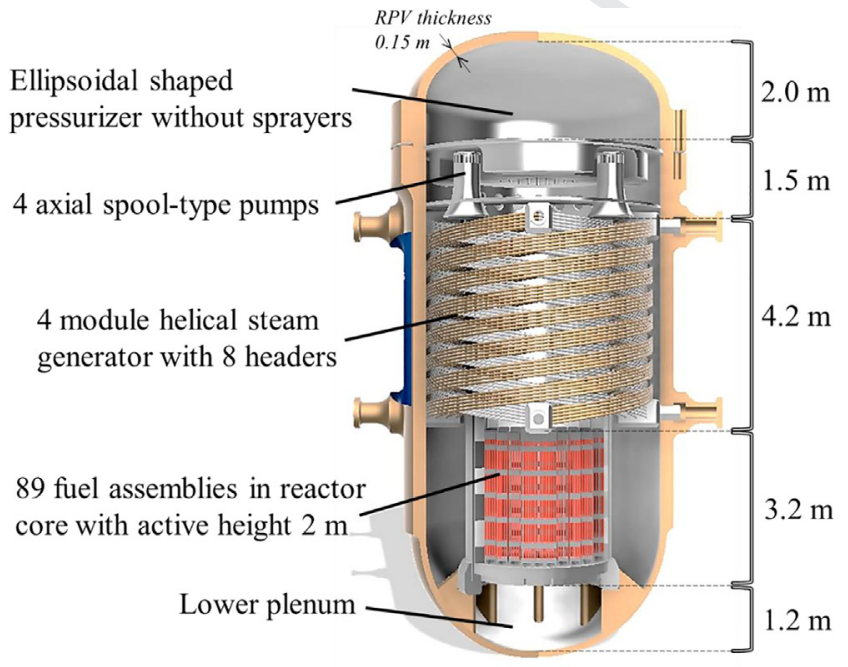

Fig. 2. Integral layout of IRIS-160.
RPV diameter can be lower than $5 \mathrm{~m}$, depending on the operation primary flowrate Calculations have been verified with the $1 \mathrm{D}$ code Relap5, which showed the potentiality for diameter reduction up to $4.6-4.7 \mathrm{~m}$. The total height of the RPV is around $12.5 \mathrm{~m}$ (Fig. 2).

\section{Safety strategy}

The safety target for emergency decay heat removal operations in a submerged SMR concept is to implement a fully passive safety approach, which does not require AC power or human interventions and can rely on the water surrounding the containment as a permanent and infinite heat sink. The achievement of this goal is fundamental for an underwater reactor, because its peculiar position would make challenging to manage in remote the safety operations in emergency situations. Passive safety would prevent by design from control errors. Beside this necessity, a fully passive strategy would represent a significant breakthrough for the nuclear safety and the application on a submerged SMR would practically allow eliminating the Fukushima-like accident scenarios.

A promising set of safety systems refers to: (i) two (or four, to be defined by PSA considerations) trains of Emergency Heat Removal Systems (EHRS), which connect the SG secondary circuit to ex-hull heat exchangers; (ii) two trains of in-pool heat exchangers, working in parallel with the EHRS; (iii) the reactor containment (drywell); (iv) a pressure suppression pool (safety tank), with direct injection lines to the RPV and to the reactor containment. According to a Fukushima-like scenario, the reference accident related to thermal-hydraulic is only the Station Black-Out (SBO), since the concurrent Loss of Ultimate Heat Sink (LUHS) is assumed as practically impossible. Hence, the basic accident scenario begins with the loss of ordinary active cooling capabilities, automatic reactor scram and actuation of passive safety systems. Then, two reference situations can be identified according to one single criterion: the integrity (or not) of the primary circuit. The safety procedure adopts, in an "intact primary" (non-LOCA-SBO) scenario, the passive EHRS, to reject the decay heat to the infinite heat sink (sea or lake) and/or the in-pool heat exchangers, to reject the decay heat to the suppression pool (Fig. 3a). In a "non-intact primary" (LOCA-SBO) scenario, after the immediate emergency injection from high-pressure systems, the strategy is: (i) opening of check valves between RC and ST to move steam and non-condensable gases into the suppression pool; (ii) opening of direct injection lines to the integral RPV (exploiting pool over-pressure); (iii) flooding of the reactor compartment and condensation on the inner wall of the containment. The final state is called "depressurized and flooded" safe state, i.e. a targeted situation where the reactor containment is flooded by the injection of water from a large safety tank to the depressurized primary system. It is shown in Fig. 3b. The latter represents also a backup strategy in case of failure of other safety systems.

\section{Simulation of the long-term cooling scenario}

\subsection{Overview}

The keystone of submerged SMR safety strategy is the demonstration that the designed systems can provide adequate passive decay heat removal under any circumstances and for an indefinitely long time. This condition depends on the feasibility of the depressurized and flooded safe state. Depressurization may be the consequence of a LOCA or induced by ADS opening in case of failure of other safety systems.

The scenario here considered is the long-term core cooling process of a pressurized SMR placed on the seafloor, after a rupture of the primary circuit. Simulations have been performed using the 1D 


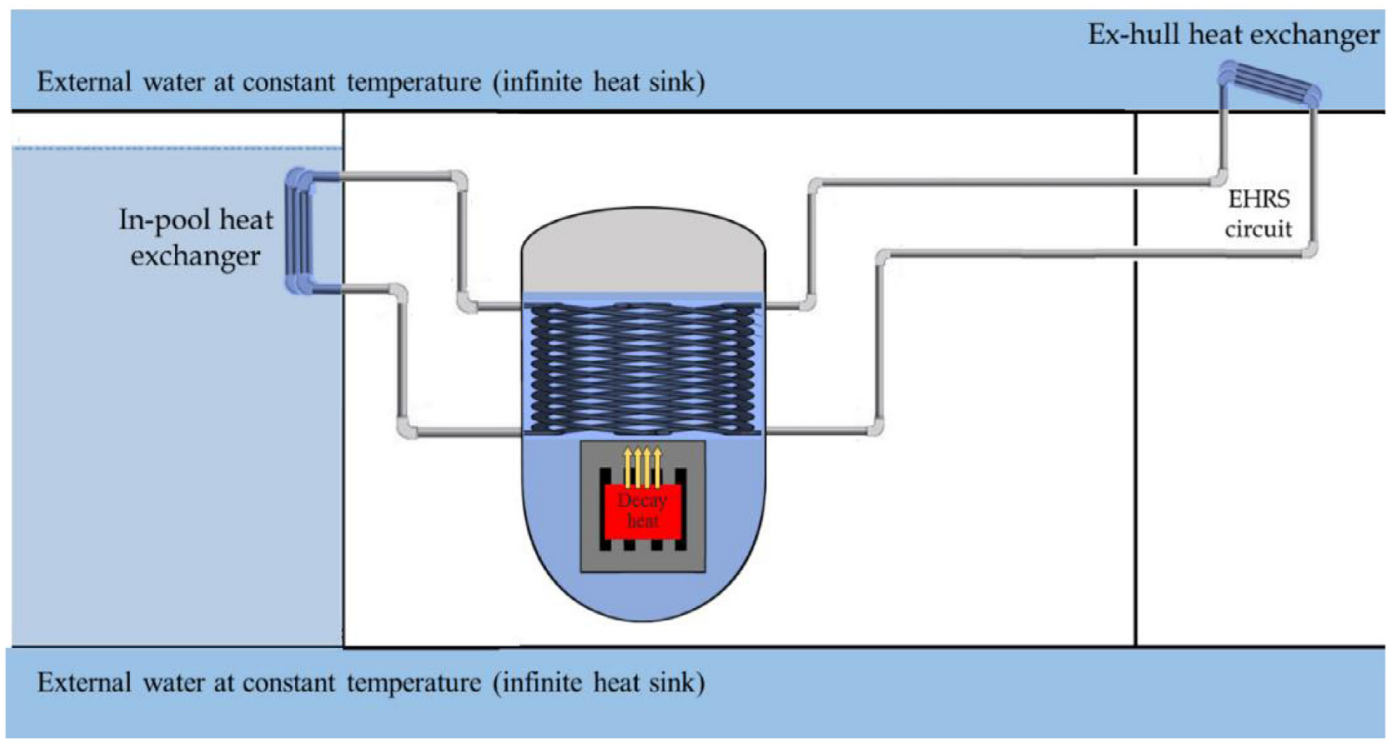

(a)

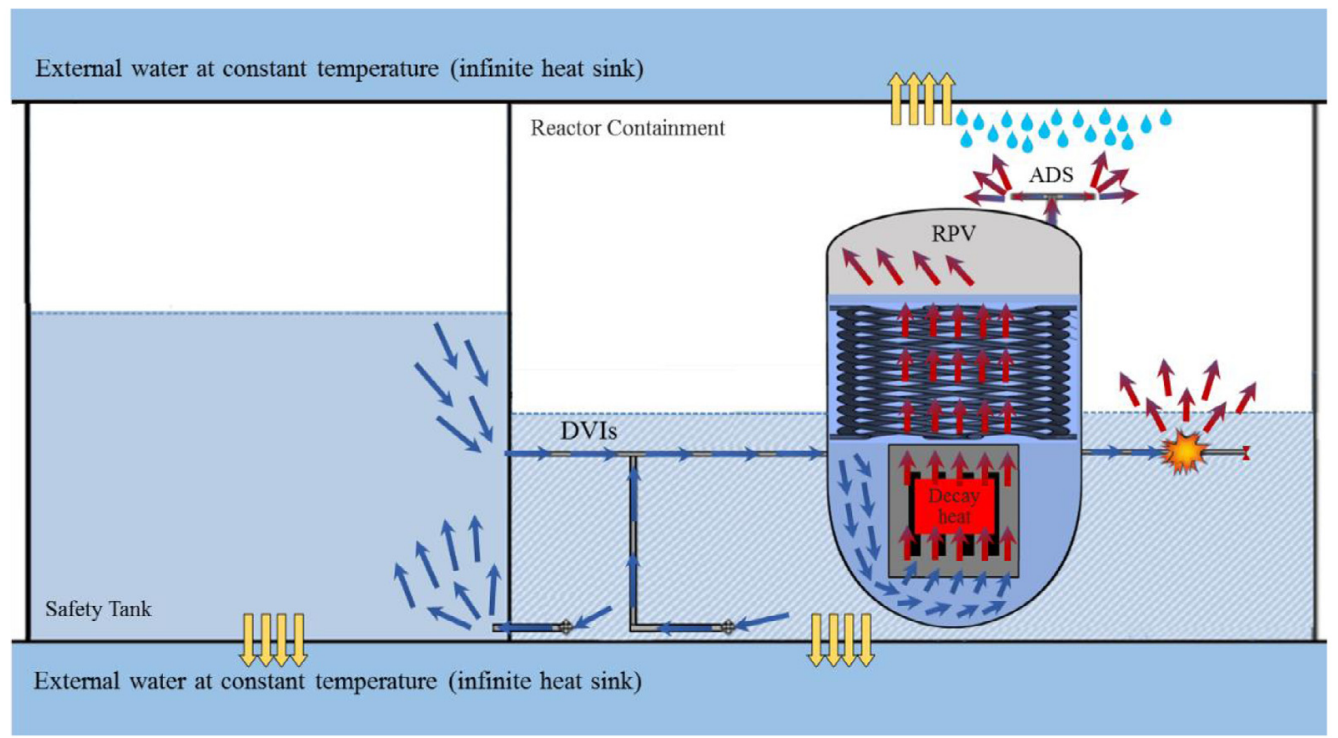

(b)

Fig. 3. Principles of safety strategy for intact (a) and non-intact (b) primary system scenarios (dimensions are not representative).

system code Relap5/Mod.3.3 and following the guidelines provided by U.S. NRC Nuclear Safety Analysis Division (U.S. NRC Nuclear Safety Analysis Division, 2003). The reference situation is a 500 $\mathrm{MW}_{\text {th }}$ PWR-like reactor placed in a submerged large horizontal cylinder, which undergoes a LOCA or a depressurization induced by ADS opening. In case of LOCA, following the initiating event, reactor scram automatically occurs and high-pressure emergency injection and steam suppression systems operate in the period immediately after the beginning of the accident. They are aimed at managing the pressure peak, moving non-condensable gases to the suppression pool and removing heat from the core when the decay power is high. Haratyk and Gourmel (2015) have described and simulated such sequence both for large and small break LOCA in Flexblue reactor. After this phase, which is estimated to last approximately $7-8 \mathrm{~h}$, the over-pressure and the water level in the suppression pool should be able to drive the DVIs injection and the flooding of the reactor compartment. In such conditions, the natural circulation flow shown in Fig. 3 is established, driven by the difference of pressures and water levels between the sup- pression pool and the reactor compartment. Decay heat is removed from the core and rejected through the metal containment to the surrounding seawater, which acts as an infinite heat sink. This process is expected to provide a continuous and efficient cooling of the fuel rods, ensuring a potentially unlimited grace period.

The transient begins $7 \mathrm{~h} 30^{\prime}$ after the reactor scram, when the water stored in the suppression pool has been already released to flood the reactor compartment. At that time, the decay heat produced by the fuel rods is around $4 \mathrm{MW}_{\mathrm{th}}$. In this analysis, the LOCA event and the operation of components to provide immediate coolant injection have not been simulated, since the focus is the longterm decay heat removal. The two reference simulations explore the heat transfer process in the first day after the scram and until the core power is $1 \mathrm{MW}_{\mathrm{th}}$, i.e. approximately 21 day later.

\subsection{Model and nodalization}

A sketch of the system considered for this activity is shown in Fig. 4. The system is composed of three macro-components, i.e. 


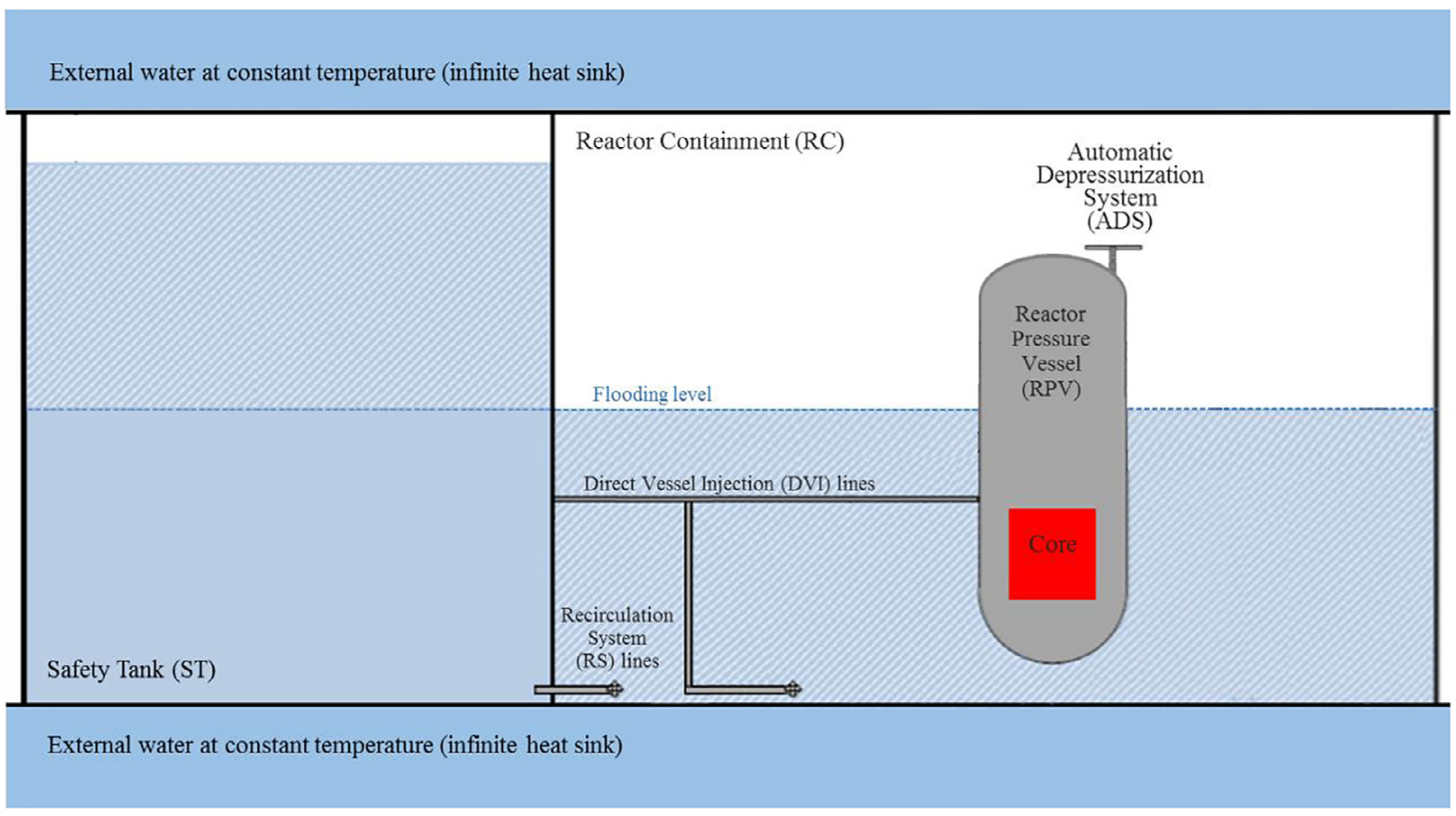

Fig. 4. Sketch of the system considered in this work (dimensions are not representative).

the Reactor Pressure vessel (RPV), the Reactor Containment (RC) and the Safety Tank (ST), jointed by three groups of piping, i.e. the Direct Vessel Injection (DVI) lines, the Automatic Depressurization System (ADS) and the Recirculation System (RS). The reactor type here considered is a generic pressurized reactor. This study has been supported by DCNS, who advised to simulate the reactor configuration used for Flexblue preliminary safety analyses. However, the purpose of the analysis is to study the characteristic of an infinite heat sink: given that the RPV is already depressurized at the starting point of the simulation, the layout of the reactor has a limited impact on the behavior of the natural circulation.

The RPV model (Fig. 5a) reflects the simplified design of a typical pressurized water reactor: it is made of the downcomer, the lower plenum, the core and the upper plenum. Each component is modeled using elementary volumes connected by junctions. To avoid the onset of unphysical recirculation flows, the model of the core is made with a single vertical channel. The heat source is placed into the active zone of the core, which is made of 12 elementary volumes. Since only one pipe is used to simulate the core region, the radial power distribution in the core is neglected. On the contrary, the axial cosine-shaped power distribution is considered. Form losses coefficients are set into the core region to simulate the concentrated pressure drop given by the spacing grids.

The nodalization of the two containments, i.e. RC and ST, in Relap5 is a hard task, since it is a "pipe oriented" code and it is not optimized for analysis of large volumes. A sliced model is here used: the total volume of each containment is subdivided into two parallel pipes, upward vertically oriented, made of 56 elementary volumes connected by transversal crossflow junctions, as shown in Fig. $5 \mathrm{~b}$ and c. Each element is characterized by volume, hydraulic diameter and heat transfer area. Each junction is characterized by the cross section. A similar approach was proposed by Papini et al. (2011): they tested the sliced model on a case-study and compared the results with the predictions of the code GOTHIC, a specific tool for the simulation of large containments, observing an acceptable agreement. Pipes are provided with heat structures that simulate the conductive thermal resistance of the containment and the convective heat transfer given by the natural circulation of the exter- nal water. This approach to the spatial discretization may present some criticalities, such as the modeling of the heat structure geometry: Relap5-Mod3.3 allows only rectangular, cylindrical and spherical geometry and the rectangular option has been selected for this work. However, it offers at least three advantages: (i) it permits a good vertical resolution of the liquid and gas phases in the containments; (ii) thanks to the two pipes, it permits to observe flow recirculation; (iii) it allows using a non-uniform discrete profile for the external heat transfer coefficient (Fig. 6).

\subsection{Boundary and initial conditions}

To study the system under investigation with a 1D code, two thermal boundary conditions are required where heat structures simulate boundary heat transfer processes. Second type boundary condition (fixed-power conditions) has been adopted to simulate decay heat generation in the fuel rods and third type boundary condition (convective condition) for the external seawater natural circulation. Heat transfer between RPV and RC pool has been neglected in this study. Initial conditions at $7 \mathrm{~h} 30^{\prime}$ after the scram are determined thanks to conservative and reasonable assumptions.

The heat structure that simulates fuel rods is composed of an inner UO2 cylinder, which contains a volumetric heat source, surrounded by a Zircaloy- 4 annulus, which represents the cladding. The decay curve proposed by ANS 2005 Standard is used (Shwageraus and Fridman, 2012) to simulate a 25-hour-long reference transient. In addition, an accelerated decay curve is used besides the standard one. The accelerated transient allows investigating the behavior of the sump natural circulation flows up to 21 days after the scram. Both curves assume the decay power $7 \mathrm{~h} 30^{\prime}$ after the scram as initial value. A comparison between the two profiles is given in Fig. 7 . The use of such accelerated decay curve is an obligated choice in order to simulate, within a manageable computational load, the behavior of the system up to several days/weeks after the scram, thus addressing the main purpose of the study. However, such approach represents a strong hypothesis on the system evolution and poses some warning about the con- 


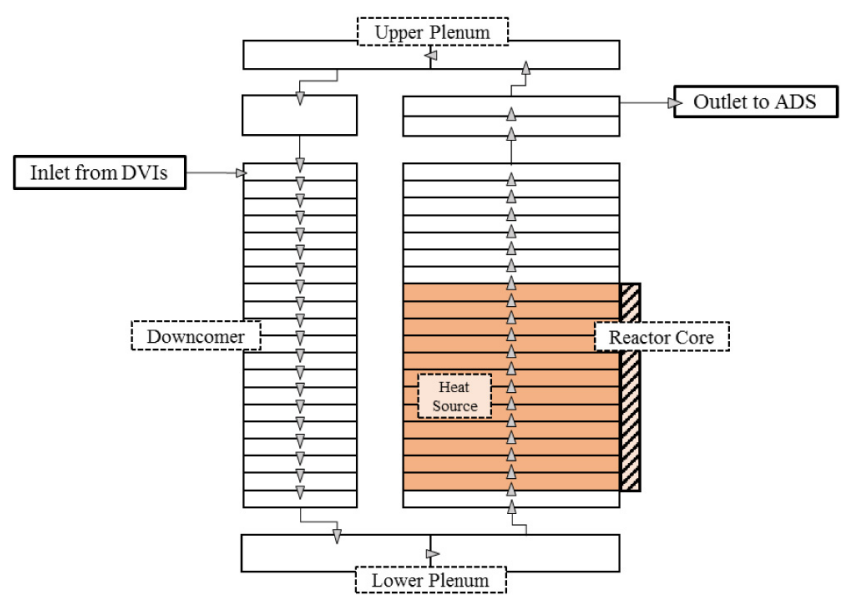

(a) Reactor Pressure Vessel
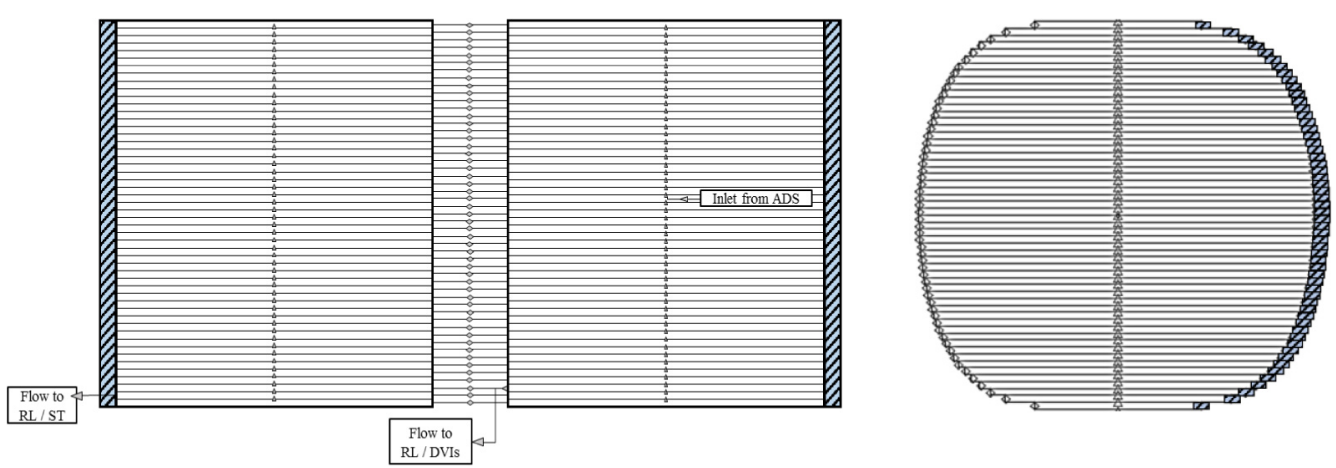

(b) Reactor Containment (front view and "side" view)
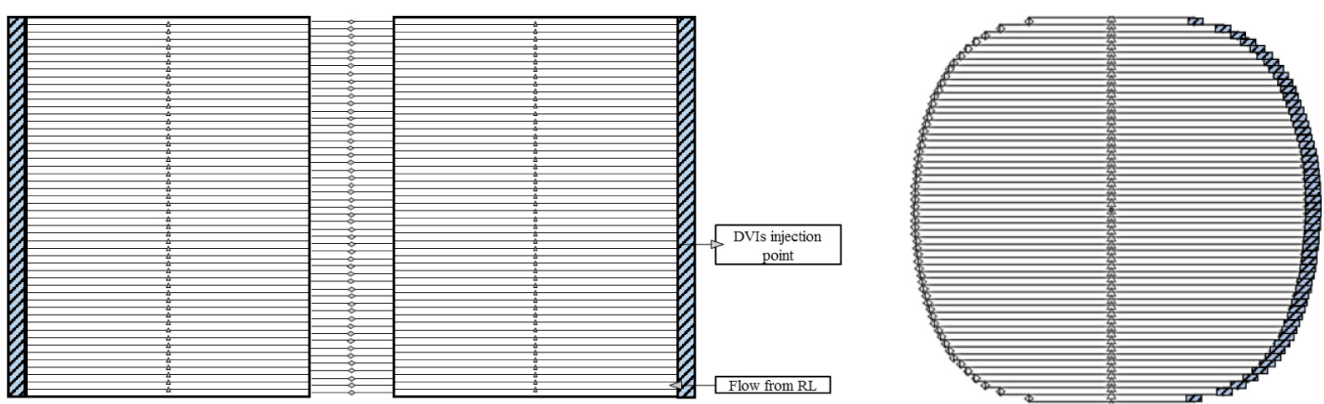

(c) Safety Tank (front view and "side" view)

Fig. 5. Nodalization of RPV (a), RC (b) and ST (c). The
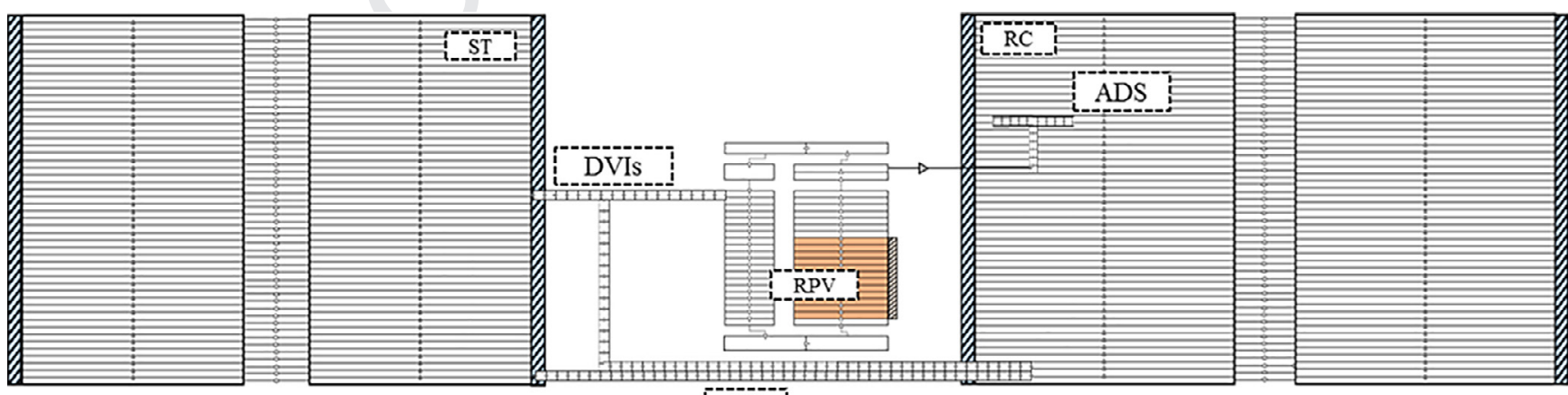
RS

Fig. 6. Complete model (dimensions are not representative). 


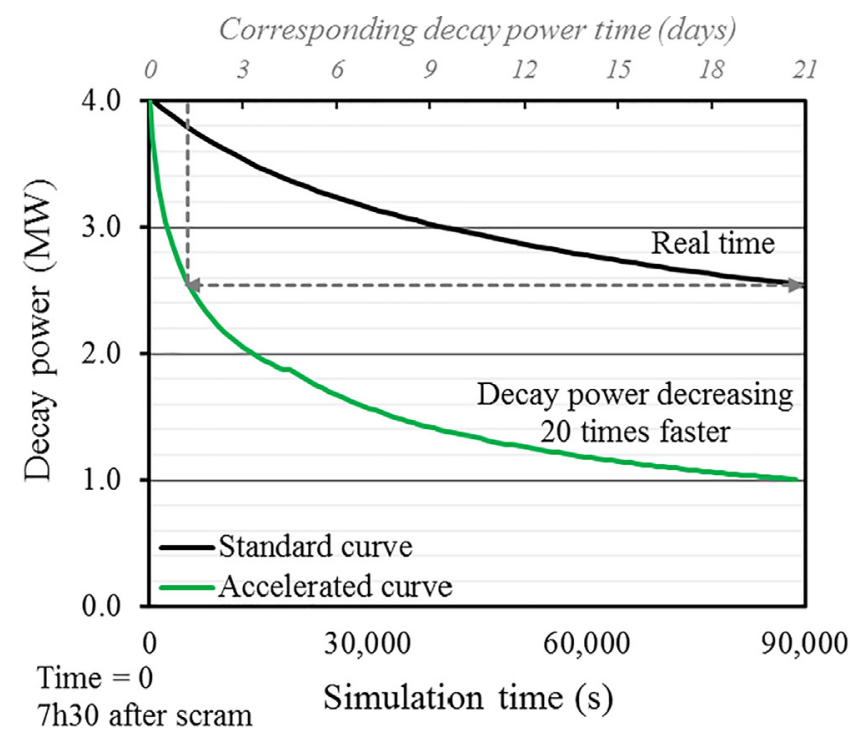

Fig. 7. Decay curves used for the simulation. The zero point on the $x$-axis represent the starting point of the simulation, i.e. $7 \mathrm{~h} 30^{\prime}$ after the scram.

servativeness of the assumption: although it reduces the buoyancy force in the core more rapidly than in the real case, it also underestimates the amount of heat transferred to the RC within the simulation period. Notwithstanding this consideration, one can observe that the thermal inertia of the water inventory in the ST and in the RC is very large. Therefore, the impact of that underestimation on the results is believed to be quite limited and allow focusing the attention on the hydro-dynamic aspects of the sump natural circulation flow when core decay power is low. To complete the investigation, an additional simulation is performed considering a constant and very low core power, equal to $0.4 \mathrm{MW}$. This value represents the decay heat of the reactor approx. 4 months after the scram. For this case, the output of the simulation with the accelerated curve is used to determine initial conditions. The conclusions of the study are then deduced from all the three cases.

The heat structures associated to RC and the ST take into consideration the conductive thermal resistance of the reactor containment and the external natural convection. A convective boundary condition is used to avoid modeling the external water. The results of a previous study (Santinello et al., 2017) (Fig. 8) about the external natural circulation from a submerged horizontal

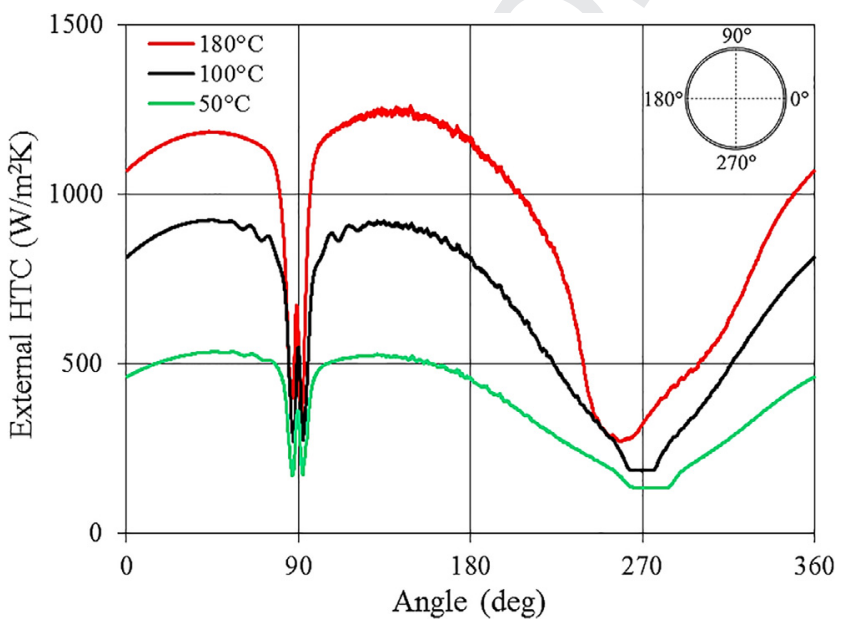

Fig. 8. Results of the CFD study about the external HTC in (Santinello et al., 2017), for three uniform internal RC temperatures and $\mathrm{T}_{\infty}=35^{\circ} \mathrm{C}$. cylindrical containment are employed to define the heat transfer coefficient (HTC). Seven discrete constant values are set, as shown in Fig. 9, since the profile of the HTC is not uniform along the perimeter of the containment. Undisturbed seawater temperature has been fixed to $20^{\circ} \mathrm{C}$.

Definition of initial conditions is a difficult aspect of the study, since the conditions of the system $7 \mathrm{~h} 30^{\prime}$ after the initiating event of the accident are not known. During the initial transient, the system evolves without any human intervention or AC power: several heat transfer, phase change and mixing processes occur and the thermal-hydraulic conditions of the system are not predictable. Approximated and/or conservative estimations have been made a priori for pressures, temperatures and phases conditions. The chosen initial conditions are reported in Table 1. In particular, the initial temperature of the water stored in RC and ST, equal to $50^{\circ} \mathrm{C}$, is strongly conservative: if all the decay heat produced in $7 \mathrm{~h} 30^{\prime}$ after the scram was transferred to the water stored only in the RC with no heat transfer to the exterior (as in Eq. (1)), the temperature would increase from $20^{\circ} \mathrm{C}$ to $46^{\circ} \mathrm{C}$.

$\mathrm{T}_{\mathrm{i}}-\mathrm{T}_{\mathrm{ext}}=\frac{\int_{\mathrm{scram}}^{7.5 \mathrm{~h}} \dot{\mathrm{Q}}(\mathrm{t}) \mathrm{dt}}{\mathrm{m}_{\mathrm{RC}} \mathrm{c}_{\mathrm{p}}} \approx 26^{\circ} \mathrm{C}$

$\mathrm{T}_{\mathrm{i}}=$ initial $\mathrm{RC}$ temperature $\left({ }^{\circ} \mathrm{C}\right) ; \mathrm{T}_{\text {ext }}=$ external temperature $\left({ }^{\circ} \mathrm{C}\right)$; $\dot{Q}(t)=$ decay power function; $c_{p}=$ specific heat $(\mathrm{J} / \mathrm{kgK}) ; \mathrm{m}_{\mathrm{RC}}=$ water inventory in $\mathrm{RC}(\mathrm{kg})$.

\subsection{Results}

The combination of three simulations, i.e. standard curve, accelerated curve and low-power, allows investigating the sump natural circulation flow from few hours after the scram to the long-term period. The analysis with the standard curve firstly shows that the containment is capable to reject a large amount of heat even when the decay power is high. Then, the accelerated transient and the low-power case reveals that the sump natural circulation flow should be still effective several days/weeks after the scram. Steam is produced into the core, condenses in contact with the $\mathrm{RC}$ wall and the condensate falls by gravity into the flooded zone. Pressures and levels of liquid in RPV, RC and ST are summarized in Table 2. Such values confirm the feasibility of the natural circulation flow. Because of the presence of nitrogen and steam, pres-

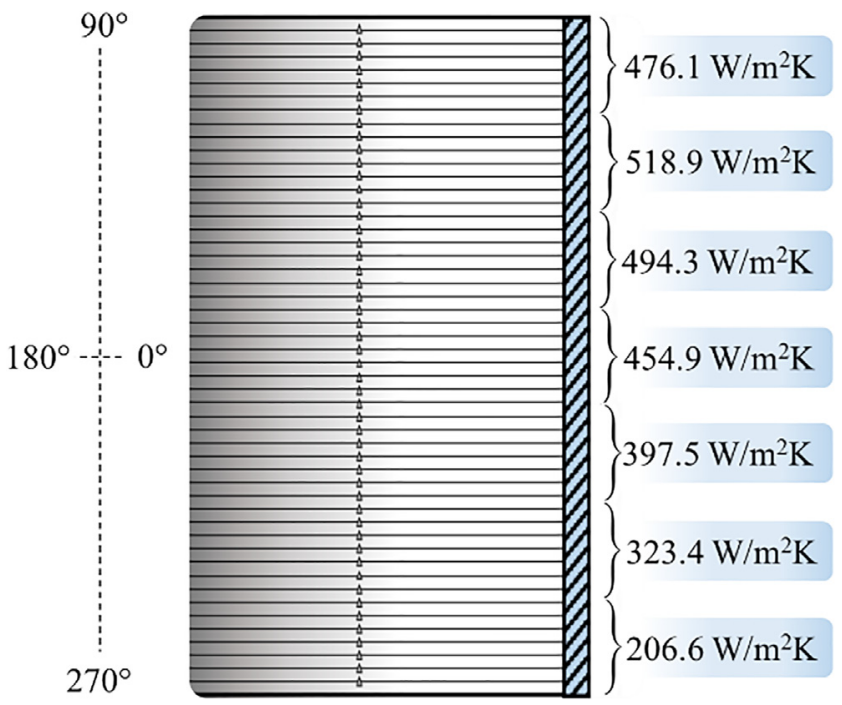

Fig. 9. HTC values used in the present study, based on $50{ }^{\circ} \mathrm{C}$ case (green curve in Fig. 8). (For interpretation of the references to colour in this figure legend, the reader is referred to the web version of this article.) 
Table 1

List of initial conditions for cases with standard and accelerated curves.

\begin{tabular}{|c|c|c|c|}
\hline & Reactor Pressure Vessel & Reactor Containment & Safety Tank \\
\hline Pressure & $0.2 \mathrm{MPa}$ & $0.2 \mathrm{MPa}$ & $0.2 \mathrm{MPa}$ \\
\hline Temperature & Saturation in upper plenum $100^{\circ} \mathrm{C}$ elsewhere & $\begin{array}{l}100^{\circ} \mathrm{C} \text { for gas zone } \\
50^{\circ} \mathrm{C} \text { for liquid zone }\end{array}$ & $50^{\circ} \mathrm{C}$ for both liquid and gas volumes \\
\hline Level of liquid & Steam in upper plenum, liquid elsewhere & $7 \mathrm{~m}$ & $7 \mathrm{~m}$ \\
\hline Non-condensable & - & $100 \%$ nitrogen & $100 \%$ nitrogen \\
\hline
\end{tabular}

sure in RC is higher than in ST, hence the flow in the recirculation line is such that liquid water flows from RC to ST, increasing the level of liquid of the latter with respect to initial conditions. The head in the ST is sufficient to push cold water in the DVIs and to cool the fuel rods. The feedwater in the DVIs flows from the ST/ $\mathrm{RC}$ to the RPV, ensuring a continuous and stable injection. This process is sketched in Fig. 10.

The simulation with the standard decay curve represents the evolution of the system for $25 \mathrm{~h}$ after the starting point taken at $7 \mathrm{~h} 30^{\prime}$ after the scram, given the initial conditions in Table 1 . The results confirm the good capability of the metal containment to reject decay power through the containment. Except for the first $1000 \mathrm{~s}$, which are affected by the conservative initial condition about non-condensable mass fraction, heat transfer rate to the

Table 2

Pressures and levels of liquid of the three simulation cases.

\begin{tabular}{llll}
\hline & & Pressure & Level of liquid \\
\hline Standard curve & RPV & $0.247 \mathrm{MPa}$ & $4.95 \mathrm{~m}(5.90 \mathrm{~m})^{1}$ \\
& RC & $0.258 \mathrm{MPa}$ & $6.04 \mathrm{~m}(5.56 \mathrm{~m})^{2}$ \\
& ST & $0.237 \mathrm{MPa}$ & $8.01 \mathrm{~m}(2.11 \mathrm{~m})^{3}$ \\
Accelerated curve & RPV & $0.228 \mathrm{MPa}$ & $5.49 \mathrm{~m}(6.42 \mathrm{~m})^{1}$ \\
& RC & $0.225 \mathrm{MPa}$ & $6.44 \mathrm{~m}(6.06 \mathrm{~m})^{2}$ \\
& ST & $0.214 \mathrm{MPa}$ & $7.55 \mathrm{~m}(1.65 \mathrm{~m})^{3}$ \\
Low power & RPV & $0.220 \mathrm{MPa}$ & $5.50 \mathrm{~m}(6.43 \mathrm{~m})^{1}$ \\
& RC & $0.216 \mathrm{MPa}$ & $6.57 \mathrm{~m}(6.19 \mathrm{~m})^{2}$ \\
& ST & $0.208 \mathrm{MPa}$ & $7.40 \mathrm{~m}(1.50 \mathrm{~m})^{3}$ \\
\hline
\end{tabular}

1 Above the bottom of RC.

2 Above the RL.

3 Above the DVIs. exterior is almost always greater than decay power, as visible in Fig. 11. The very large water inventory and the presence of external water acting as an infinite heat sink ensure that the feedwater injected into the RPV is always sufficiently cold. The largest part of the heat is removed through a liquid-liquid inner-to-outer heat transfer in the flooded part of the RC. At this step of the evolution of the accident scenario, when decay heat is less than $1 \%$ of the total power, steam production is quite low and wall condensation gives a lower contribution to the total heat transfer. However, the

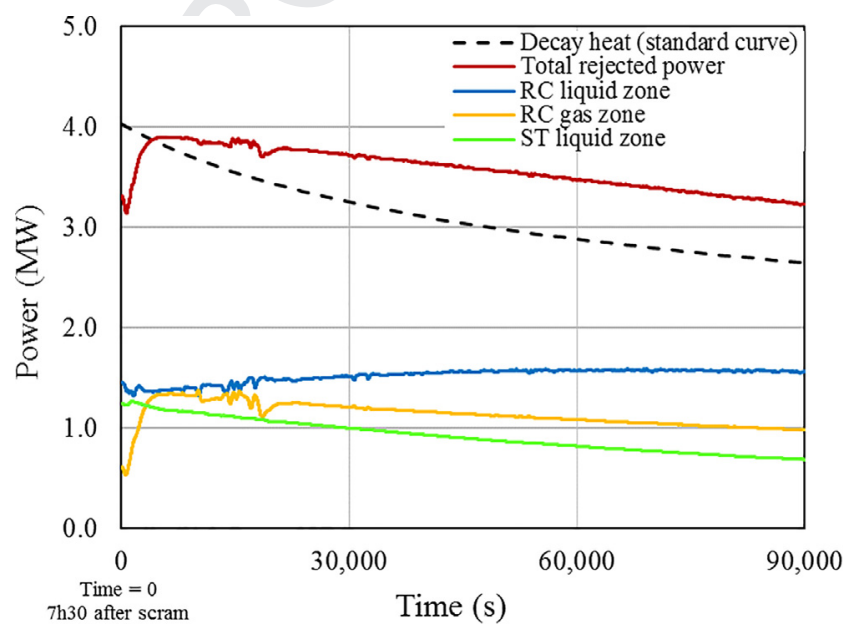

Fig. 11. Heat transfer to the exterior compared with the decay power (standard curve).

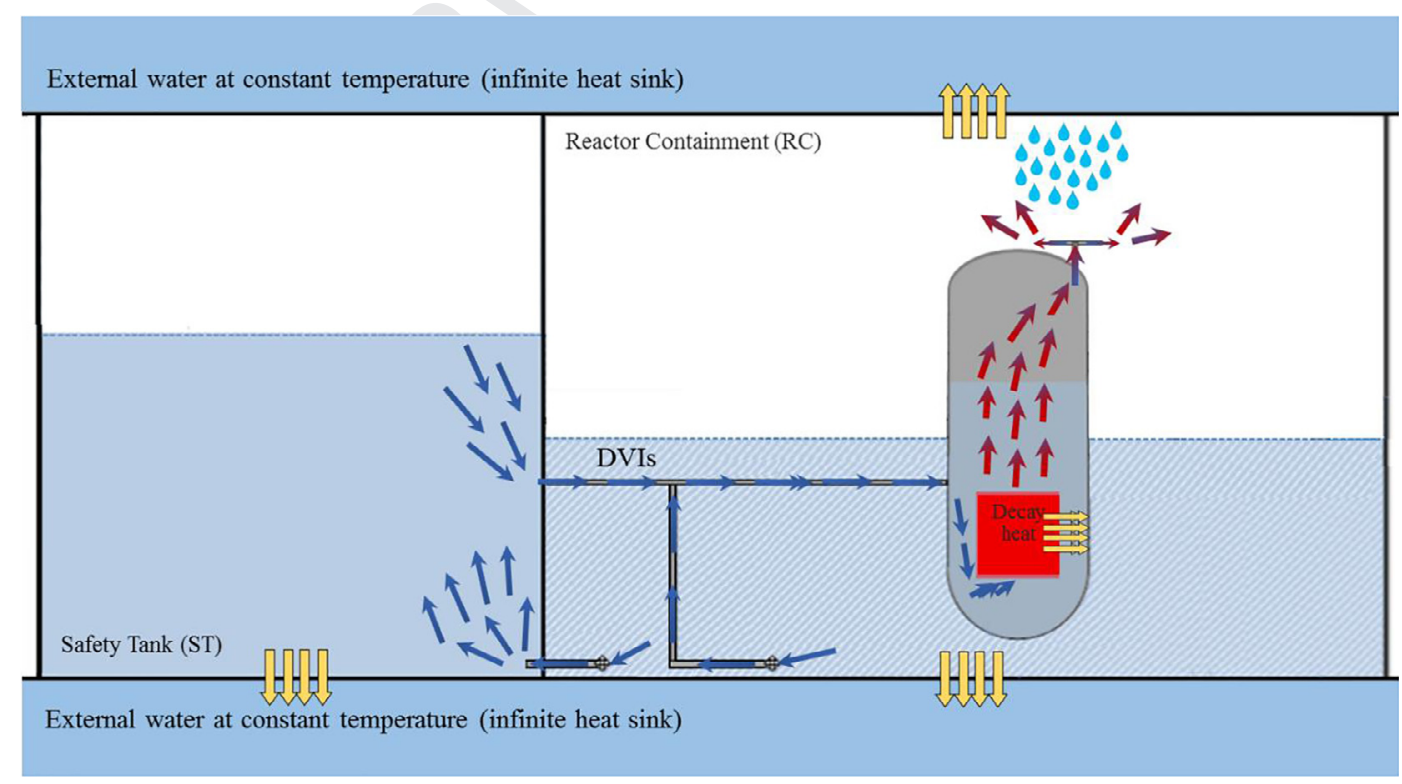

Fig. 10. Sketch of the sump natural circulation flow at the end of the simulation (dimensions are not representative). 
very conservative boundary conditions about the composition of the RC atmosphere is leading to underestimate this component.

The coolant in the core is always heated up until the saturation point: Fig. 12a shows that the quality of the coolant at the outlet of the heated zone is always slightly greater than zero. To create the density gradient necessary to sustain natural convection, the system needs to produce a small amount of steam. This production is continuous and quite regular along all the simulated period. In general, fuel rods are always adequately cooled: the mass flow rate through the core allows the removal of the decay power, showing no critical issues for the thermo-dynamic conditions of the coolant and for the temperature of the fuel cladding. Decay heat is taken away both by the vapor and liquid phases, whose velocities are positive. (Fig. 13a).

The large thermal capacity of the water inventory stored into the ST and the presence of the external water acting as an infinite heat sink provide great benefits to the core cooling process. Firstly, the amount of heat that can be stored into the safety tank is very high: even under conservative assumption, the temperature profile of the flooded zone of the RC always remains far below the saturation point. Then, the RC and ST are continuously cooled by the external water through the metal containment and the pool average temperature undertakes a decreasing trend after few hours of simulation (Fig. 14a). Such liquid-to-liquid heat transfer is very efficient and represents the major way for heat transfer to the external water. This process ensures the presence of cold feed water for core cooling during the whole simulated transient. The steam generated condenses on the internal surface of the RC. Condensation heat transfer gives a lower contribution, but this process is likely to be affected by the very conservative initial conditions about the non-condensable mass fraction in the RC. Actually, the steam suppression system is supposed to operate immediately after the LOCA, thus removing a large part of non-condensable gases.

Fig. 12b-13b-14b regard the transient with the accelerated decay curve. At the end of the simulation time, the core power assumes the value that the standard decay curve reaches nearly 21 days after the scram. The results of the simulation assess the behavior of the passive safety systems under the given layout, water inventory and boundary/initial conditions. The long-term sump natural circulation flow is sustained also by a smaller power. This is noticed for decay power input ranging from 4 to $1 \mathrm{MW}$. A small production of steam in the core is necessary to maintain the density gradient and drive the natural circulation flow.

Similar conclusions can be drawn also from the low-power case. The low power simulation allows evaluating the behavior of the sump natural circulation flow when the core decay power, and consequently buoyancy force, has strongly decreased with respect to the simulation with the standard curve. According to the results, even with a low decay heat, i.e. 0.4 MW constant, the sump natural circulation flow is operating and requires the production of steam in the core (Fig. 15). The outlet quality is however very low. In such circumstance, the capability of the containment to reject heat to the exterior is much higher than the decay power (Fig. 16).

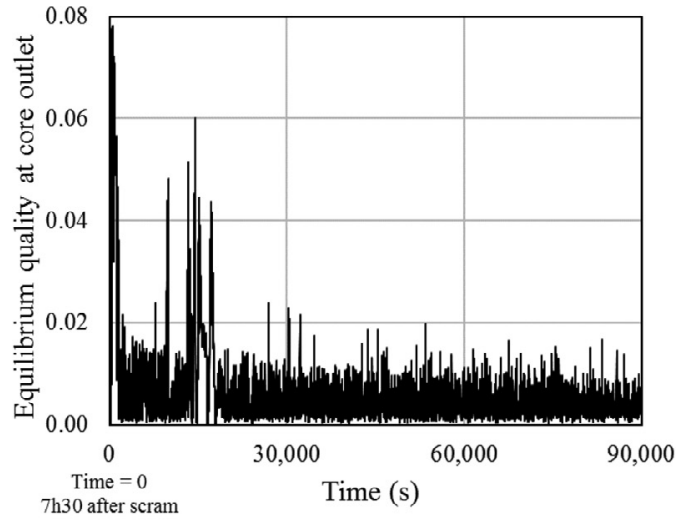

(a)

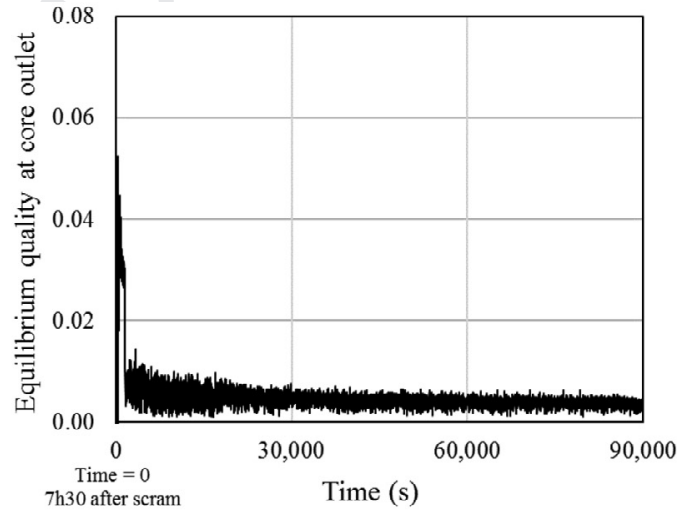

(b)

Fig. 12. Quality profile at core outlet for standard (a) and accelerated (b) curves.

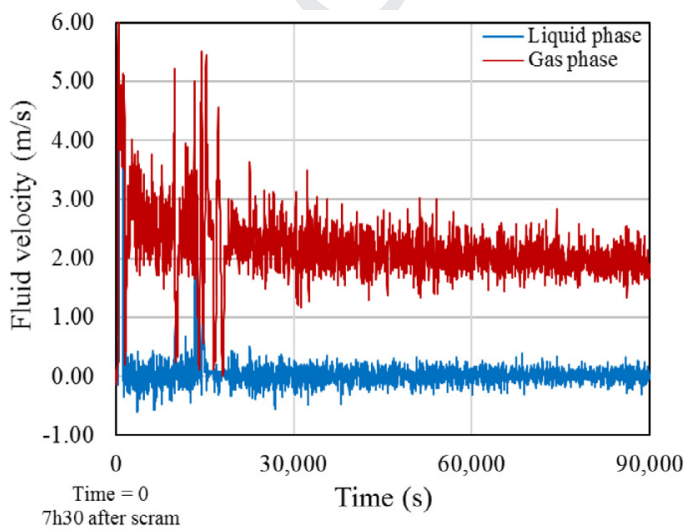

(a)

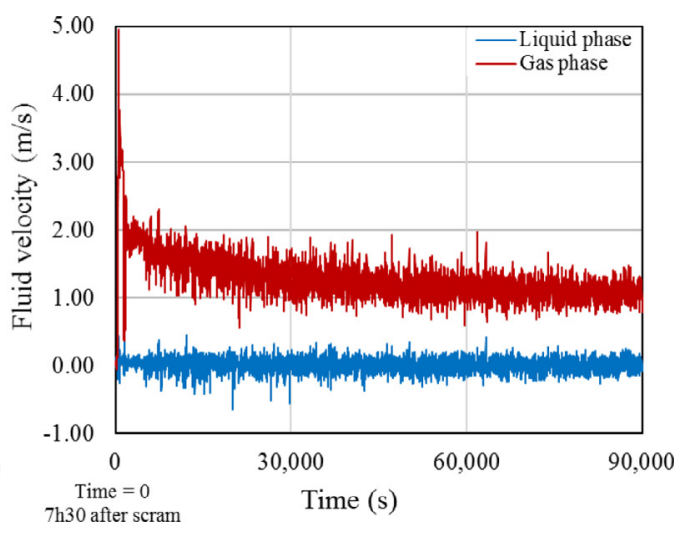

(b)

Fig. 13. Velocity profile in the hot legs for standard (a) and accelerated (b) curves. 


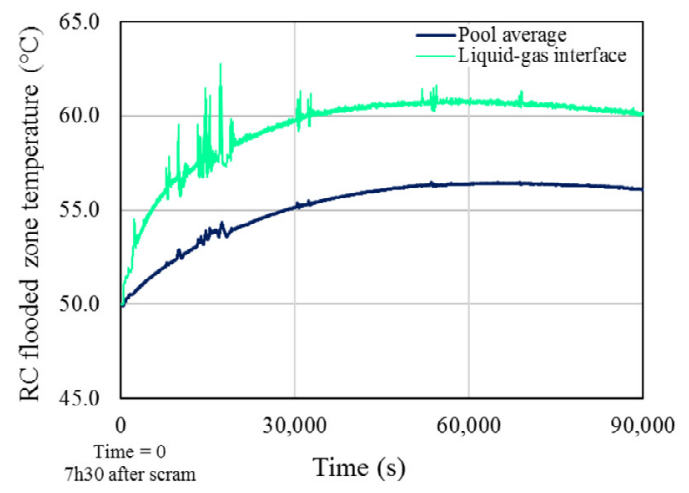

(a)

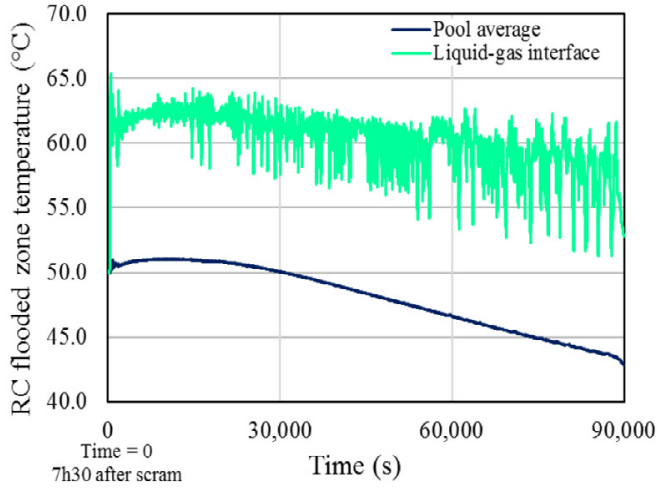

(b)

Fig. 14. Temperature profiles in the RC pool for standard (a) and accelerated (b) curves.

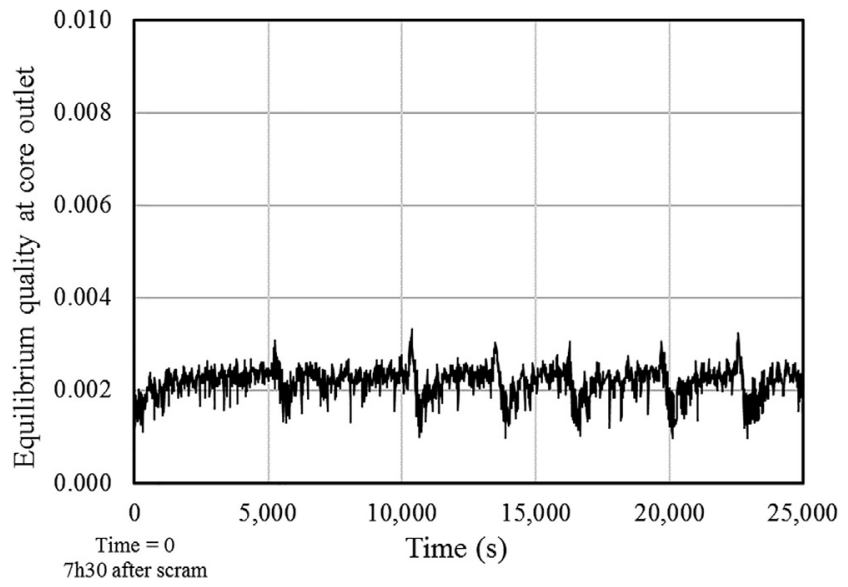

Fig. 15. Quality profile at core outlet for low power simulation.

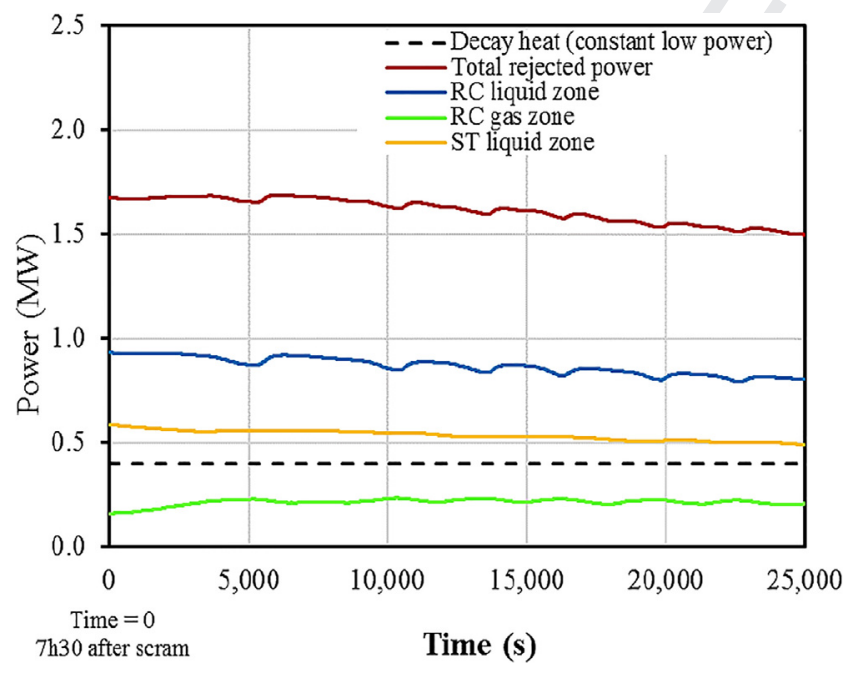

Fig. 16. Heat transfer to the exterior for low power simulation.

In conclusion, a concept of passive safety systems based on a submerged containment and sump natural circulation flow can cool the fuel rods for a potentially unlimited period. The collapsed liquid level is always above the top of active core in the three cases (Fig. 17). The temperature profile of the RC pool in Fig. 14 is significant in order to verify the consistency of the approach based on

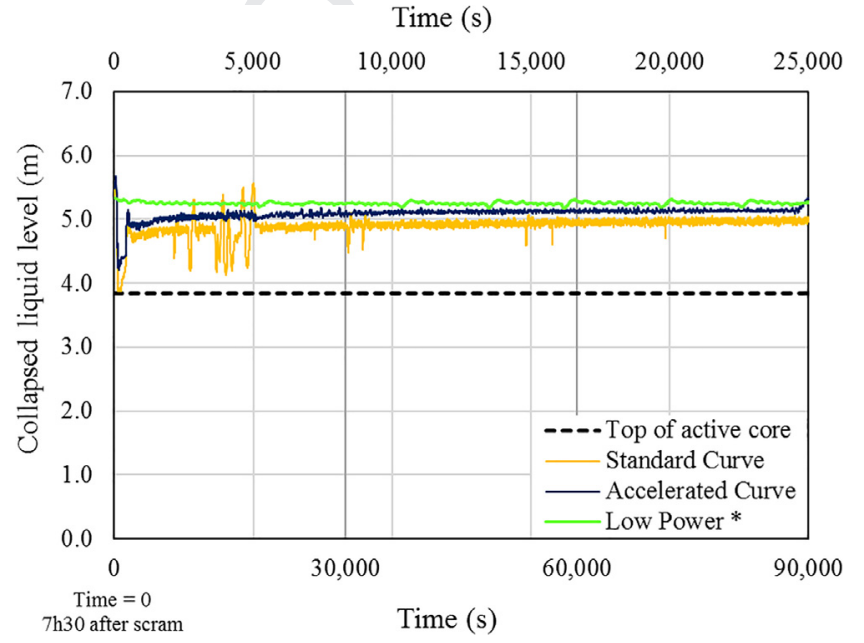

Fig. 17. Collapsed liquid level: height from the bottom of RPV $\left({ }^{*}\right.$ time on the upper $\mathrm{x}$-axis).

the accelerated decay curve. It is observable that the RC pool temperature profile has a maximum and a then decreasing trend also in the simulation with the standard curve, i.e., within the first day after the scram. Therefore, it is sure that the simulation with the accelerated curve is not neglecting an accumulation of heat inside the RC pool using the accelerated curve.

\subsection{Sensitivity on the nodalization of containments}

Nodalization of containments (RC and ST) is a complex task, since Relap5 is a 1D system code and in general it is not considered the first choice when modeling of containments is required. Relap5 solves fluid balance equations considering the linear coordinate, while constitutive models account for phenomena with transverse gradients (e.g. friction and wall heat transfer). In principle, the application to a large volume with a mixture of steam and noncondensable gas in free convection goes beyond the limits of proper use of the code, even though with an accurate nodalization strategy acceptable results can be obtained (Papini et al., 2011). This aspect represents the most critical issue of the spatial discretization and probably the largest source of numerical uncertainty. In the current study, the necessity of simulating the behavior of multiphase and multicomponent flow in large containments is addressed as explained in paragraph 4.1, i.e., with two pipes subdivided into 56 elementary volumes and with crossflow 
junctions between corresponding elements. To roughly evaluate the impact of the nodalization of RC and ST on the results of the simulations, a sensitivity analysis concerning the number of elementary volumes in each pipe has been performed. It varies from 28 to 70 , i.e., $2 \times 28-2 \times 35-2 \times 47-2 \times 56$ (ref.) $-2 \times 70$, and consequently the length of each element ranges between 0.5 and $0.2 \mathrm{~m}$. All cases employ the standard decay curve.

While all these cases agree that long-term core cooling is always ensured during the simulated transient, it is observable that nodalization of RC and ST has an important influence on the general behavior of the flow. From a qualitative perspective, the results of the study are consistent, but the discretization of the containments considerably affects the stability of the results. A coarse nodalization (cases $2 \times 28$ and $2 \times 35$ ) leads to the onset of even large oscillations in the profiles of RC pressure (Fig. 18) and many other quantities (Fig. 19). Such fluctuations have a clear numerical origin and they are dumped by reducing the length of the elementary volumes. However, with a very fine refinement of the grid there is not a convergence of the results, with the case $2 \times 70$ showing a discontinuity in the behavior (green curve in Fig. 18). This analysis leaves some concerns about the sensitivity of the results to the nodalization of the containments. For cases with coarse nodalization, the length of each elementary volumes might be too large, while in the case $2 \times 70$ there can be problems

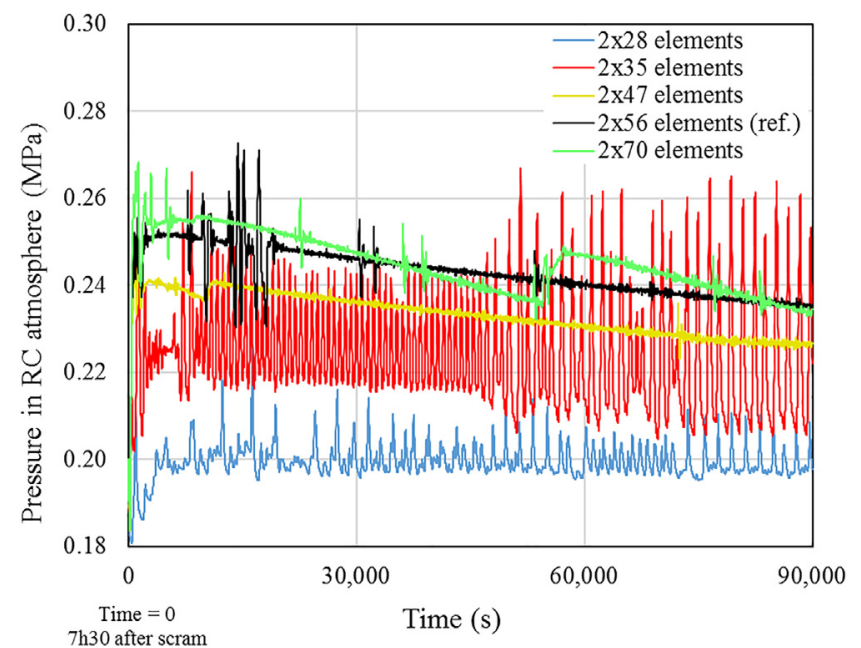

Fig. 18. Pressure profiles in the RC for sensitivity cases, compared to the reference case.

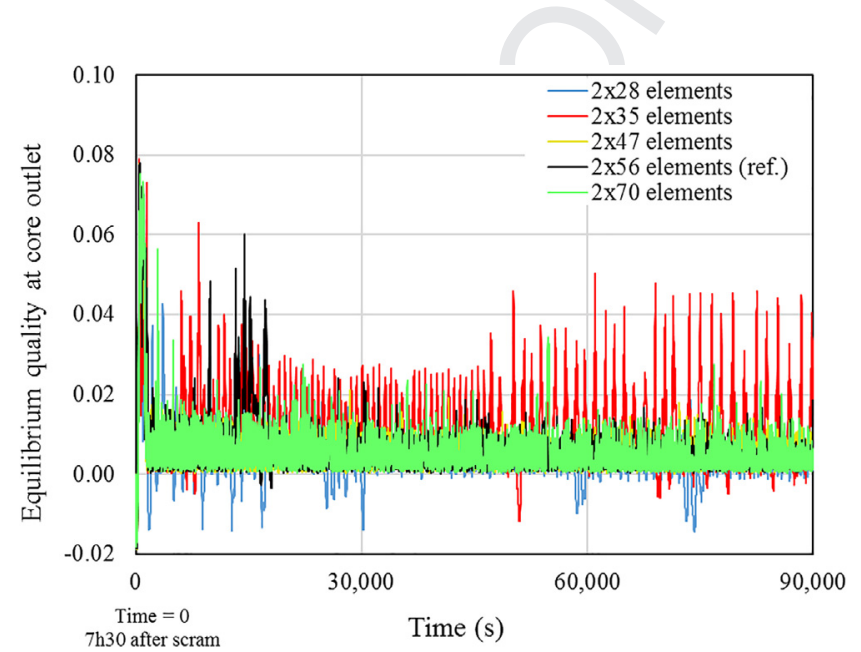

Fig. 19. Quality profiles in the RC for sensitivity cases, compared to the reference case. of distortion because of a high aspect ratio. Mass error analysis (Fig. 20) reveals acceptable results for cases $2 \times 47$ and $2 \times 56$. Reported to the total mass inventory, the mass error of the reference case is in the order of $10^{-5}$.

\subsection{Limitation of the $1 D$ approach and validation issues}

In comparison to a multi-dimensional approach, the use of a 1D scheme provides great advantages in terms of easier physical modeling and reduced computational load, making such choice suitable for a preliminary investigation. Nevertheless, the shape of the containments, a horizontal cylinder, is quite uncommon for nuclear systems, posing relevant difficulties to optimize the discretization of the circuit. Although the two-pipes sliced approach has been successfully tested by other authors, as stated in paragraph 4.2, the sensitivity analysis revealed some issues concerning the numerical stability of the results with respect to the nodalization. Comparison of results with other system codes and experimental data are mandatory. An analysis of the safety scenario with the code Apros 6, a simulation tool developed by VTT Technical Research Center of Finland, is currently under performance and has given a preliminary confirmation of the qualitative output of the results.

At date, the validation of the numerical model described in this paper is not feasible, because of the lack of databases available in open literature. The investigation of condensation in presence of non-condensable gas is very challenging, because the phenomenon is affected by a very large number of scale dependent and independent factors. Historically, the development in modeling of wall condensation without or with non-condensable gases was more theoretical than experimental. Well-known theoretical models developed by Uchida, Tagami, Dehbi, Kataoka, Murase and Liu, described and compared by IAEA (IAEA, 2005), are valid only for defined scopes, while for regulation purposes authorities often use conservative approaches based on the Uchida correlation. Experimental investigations performed in various scales have been described by many authors (Choi et al., 2011) (Funke et al., 2012) (IAEA, 2012), but the large surface of the containment requires either a specific scaling or examination of the section (IAEA, 2005). Moreover, for both approaches the setting of representative boundary conditions is extremely difficult and in the current case the mutual interaction between internal condensation and external natural convection also needs to be studied.

A specific experimental facility for model validation was proposed in the framework of an R\&D project submitted to a H2020

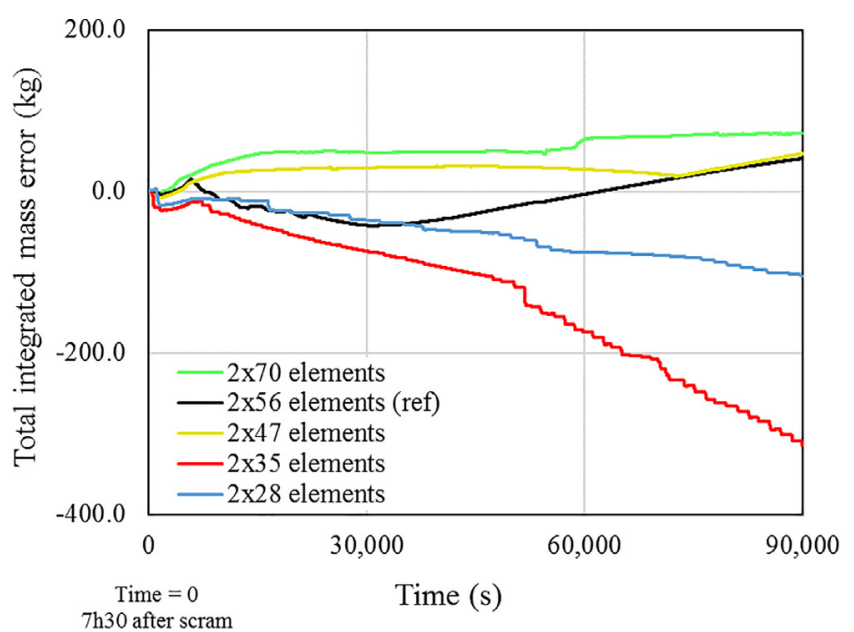

Fig. 20. Integral mass error profiles for sensitivity cases, compared to the reference case. 
Euratom call (project INSPIRE- INtegration of Smr's Potentlal Role in EU framework), led by ENEA (Ente Nazionale Energia e Ambiente) and supported by a consortium involving 13 organizations among universities, R\&D centers and industries from 6 EU countries (INSPIRE Consortium, 2016). The test section (Santinello, 2018 ) is a large-scale model, i.e. around $1: 5$, of the submerged containment of a sea-based SMR: a horizontal cylinder is representative of the containment and is immersed in a water pool, representing the sea. The reference design adopted for the investigation is the sea-based Flexblue SMR, but the layout is representative also of the Chinese ACP100 design. The facility allows both the separate effect investigation, i.e. external cooling/fluid dynamics only, and the integral effect, i.e. external cooling and internal condensation in presence of non-condensable gases.

\section{Conclusions}

This activity has proposed a conceptual reactor and safety strategy for a submerged SMR, focusing on the capability to passively cool the fuel rods following a break/depressurization of the primary loop in the long-term period. With a numerical approach, the sump natural circulation flow through the DVIs, the RPV, the ADSs, the RC, the recirculation lines and the ST has been analyzed. The calculations have been performed with Relap5-Mod3.3, adapting the one-dimensional approach of the code to the simulation of large horizontal containment. The reference case has considered the time $7 \mathrm{~h} 30^{\prime}$ after the scram as starting point, simulating the behavior of the passive safety systems for $25 \mathrm{~h}$. To allow exploring the long-term period within a manageable computational load, two additional simulations, considering an accelerated decay curve and a constant low decay power, have been performed. These cases have investigated the conditions of the systems up to 21 days and several weeks after the scram, respectively. Reasonable and conservative assumptions for the initial conditions have been made.

The study has provided a numerical demonstration of the effectiveness of the sump natural circulation flow at the basis of the passive safety concept. Considering the long-term period, a successful core cooling process has been observed in the reference simulation and in the sensitivity cases. The system benefits of the thermal capacity of the large water inventory stored into the safety tank and of the excellent heat transfer capabilities of the external seawater, acting as an infinite heat sink. A warning about the non-conservativeness of the accelerated curve assumption has been identified, although its effects do not affect the qualitative results of the simulation and are balanced by many other hypotheses, such as the very conservative initial conditions describer in paragraph 4.3. The sensitivity on the nodalization of large containments has presented some issues about the numerical stability of the simulations and the actual capability of Relap5 to simulate large containments. However, results are acceptable for a preliminary analysis. Validation of the numerical models toward specific experimental data will be necessary, as well as comparison with other system codes, as discussed in paragraph 4.6. In addition, given the importance of the RC pool temperature for the general behavior of the safety concept, a specific study about the flow circulation and heat transfer in the RC pool and in the ST should be performed, e.g., with CFD analysis.

\section{Acknowledgment}

The authors are grateful to Naval Group (DCNS) Company, in particular to Vincent Gourmel and Adam Tharreau, for providing funds and technical guidelines for the studies presented in Section 4.

\section{Appendix A. Supplementary data}

Supplementary data to this article can be found online at https://doi.org/10.1016/j.anucene.2019.03.016.

\section{References}

Blandford, E.D., Ahn, J., 2012. Examining the nuclear accident at Fukushima Daiichi. Elements 8, 188-194.

Buongiorno, J., Jurewicz, J., Golay, M., Todreas, N., 2016. The offshore floating nuclear plant (OFNP) concept. Nucl. Technol. 194, 1-14.

Carelli, M. et al., 2004. The design and safety features of the IRIS reactor. Nucl. Eng. Des. 230 (1-3), 151-167.

Choi, J., Cleveland, J., Aksan, N., 2011. Improvement in understanding of natural circulation phenomena in water cooled nuclear power plants. Nucl. Eng. Des. 241, 4504-4514.

Funke, F. et al., 2012. Iodine oxides in large-scale ThAI tests. Nucl. Eng. Des. 245, 206-222.

General Dynamics Electric Boat Division, 1971. Potential Environmental Effects of an Offshore Submerged Nuclear Power Station, s.l.: Program 16130 GFI Report for the Water Quality. Research Office of the Environmental Protection Agency.

Haratyk, G., Gourmel, V., 2015. Preliminary accident analysis of Flexblue underwater reactor. Nucl. Sci. Technol. 1 (6).

Haratyk, G., Lecomte, C., Briffod, F., 2014. Flexblue ${ }^{\circledR}$ : a subsea and transportable small modular power plant. Proc. of ICAAP ' 14.

Herring, J., 1993. Submerged Passively-Safe Power Plant. US Patent, Patent No. $5,247,553$.

Holt, M., Campbell, R.J., Nikitin, M., 2012. Fukushima Nuclear Disaster Congressional Research Service, s.l..

IAEA, 2005. Natural Circulation in Water Cooled Nuclear Power Plants. International Atomic Energy Agency, Vienna. TECDOC-1474.

IAEA, 2012. Natural Circulation Phenomena and Modelling for Advanced Water Cooled Reactors. International Atomic Energy Agency, Vienna. TECDOC-1677.

IAEA, 2016-a.. Design Safety Considerations for Water Cooled Small Modula Reactors Incorporating Lessons Learned from the Fukushima Daiichi Accident. International Atomic Energy Agency, Vienna. TECDOC-1785.

IAEA, 2016-b.. Advances in Small Modular Reactor Technology Developments - A Supplement to: IAEA Advanced Reactors Information System (ARIS). International Atomic Energy Agency, Vienna.

INSPIRE Consortium, 2016. Integration of Smr's Potentlal Role in EU framework. s.l.: Euratom Work Programme 2016-17.

International Atomic Energy Agency, 2016. Advances in Small Modular Reactor Technology Developments - A Supplement to: IAEA Advanced Reactors Information System (ARIS). IAEA, Vienna.

Kim, M. et al., 2014-b.. Conceptual studies of construction and safety enhancement of ocean SMART mounted on GBS. Nucl. Eng. Des. 278, 558-572.

Kuznetsov, V., 2012. Marine Derivative Light Water Reactor Concepts: BargeMounted and Seabed-Based Plants. Aix-en-Provence, France, s.n.

NUSMoR consortium, 2014. NUgenia Small Modular Reactor (NUSMoR) with Passive Safety Features. s.l.: EURATOM Work Programme 2014-2015.

Papini, D., Grgic, D., Cammi, A., Ricotti, M., 2011. Analysis of different containment models for IRIS small break LOCA, using GOTHIC and RELAP5 codes. Nucl. Eng. Des. 241, 1152-1164.

Reyes Jr., J.N., 2012. NuScale plant safety in response to extreme events. Nucl Technol. 178, 153-163.

Santinello, M., 2018. Study on a Submerged Small Modular Reactor: Integral Design, Passive Safety Strategy PhD thesis. Politecnico di Milano.

Santinello, M., Ricotti, M., 2018. Preliminary analysis of an integral Small Modular Reactor operating in a submerged containment. Prog. Nucl. Energy 107, 90-99.

Santinello, M. et al., 2017. External heat transfer capability of a submerged SMR containment: the Flexblue case. Prog. Nucl. Energy 96, 62-75.

Shwageraus, E., Fridman, E., 2012. Proceedings of International Youth Nuclear Congress, IYNC08, Interlaken, Switzerland, September 20-26, 2008. N.E. Todreas and M.S. Kazimi - Nuclear Systems - Vol 1 - Thermal Hydraulics Fundamental. CRC Press Taylor \& Francis Group, s.l.

Smith, M., Wright, R., 2012. Westinghouse Small Modular Reactor Passive Safety System Response to Postulated Events. Proceeding of ICAPP'12.

TEPCO, 2011. The Evaluation Status of Reactor Core Damage at Fukushima Daiichi Nuclear Power Station Units 1 to 3. Tokyo Electrical Power COmpany, s.l. http:// www.tepco.co.jp/en/nu/fukushima-np/images/handouts_111130_04-e.pdf.

U.S. NRC Nuclear Safety Analysis Division, 2003. RELAP5/MOD3.3 Code Manual, s.l.: NUREG/CR-5535/Rev P3. 